\title{
Lockdown and Insomnia among Undergraduate Healthcare Students: A Cross-Sectional Study
}

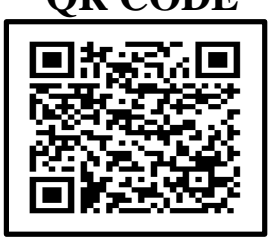

\section{RAMESH SHARMA, ANUPAM MISHRA², PRIYANKA CHATTERJEE³, ASEEM BHASKER*3}

INTRODUCTION: Insomnia is a risk factor for various physical and mental disorders as well can affect the academic performance of a student(s).

AIM: To assess the prevalence of insomnia among university going students (medical, dental and nursing streams) in the South Asian continent during the lockdown due to the COVID-19 pandemic

A MATERIALS AND METHOD: The present study was conducted amongst 743 medical, dental and nursing undergraduate students residing in South Asia using convenience sampling. Data was collected using a pre-tested and pre-validated questionnaire [the Athens Insomnia Scale (AIS)] using google forms and had a total of 8 questions (score range $0-3$ ). Final scores (the individual AIS score) were obtained by adding the scores for each question (range $0-24$ ). The higher the score was, the worse was the sleep quality; students with score of $\geq 6$ were considered insomniac. Data Analysis was done using SPSS version 21.012 by using the independent samples t-test, and multiple logistic regression.

RESULTS: A total of 921 entries were recorded, out of which 743 were complete and hence, were included in the study (response rate: $80.7 \%)$. Insomnia was reported in $421(56.7 \%)$ students, out of which, the highest was seen among dental $(62.7 \%)$, followed by medical (59.8\%) and nursing $(45.3 \%)$ undergraduates. The highest range of AIS was observed among females (6-22) and dental students (6-21). Gender differences revealed a significant association among females in both range obtained ( $\mathrm{t}$-test) $(\mathrm{p}=0.03)$ as well as the multiple linear regression analyzing insomnia in relation to gender $(\mathrm{p}=0.03)$.

CONCLUSION: There is a need to regularly assess insomnia among students and to take preventive measures incase of high prevalence is found among them, especially while pursuing academics online and from their homes due to the pandemic.

KEYWORDS: Insomnia, Sleep Deprivation, Stress

\section{INTRODUCTION}

Insomnia, a serious public health issue is a risk factor associated with various physical and mental disorders. It is classified as a disease characterized by difficulty falling and/or remaining asleep, can be accompanied with early morning awakening, daytime impairment, and/or non-restorative sleep, and may be associated with a variety of psychiatric conditions (especially depression and anxiety)., ${ }^{2,3}$

In the Asian subcontinent, a study among Chinese adolescents was reported to be $16.9 \%$ with factors associated with insomnia being age, lack of physical exercise/poor physical health, self-selected diet, longer distance from home to school, and life stresses. ${ }^{4}$ Another cross-sectional study from a sample drawn from the general population of England, Wales, and Scotland, revealed that $37 \%$ of them had insomnia. ${ }^{5}$

Researchers have documented that insomnia is a common problem in young adults, including university students and its prevalence varies as per geographic location. ${ }^{6,7}$ This can have detrimental effects on daytime activities, including studying, weakened physical, mental functions and lowered work productivity. It can also lead to anxiety and depression among students. ${ }^{2,8}$ It has been observed that the Grade Point Average (GPA) of a student is significantly associated with the duration of sleep; and insomnia decreases the ability to perform basic academic activities such as solving mathematical problems among students. ${ }^{9}$

As already the university student was under immense stress, the COVID-19 pandemic has wreaked havoc in their lives, especially international students who have been forced to remain in their native country due to travel bans/imposition. While teaching shifted to the online medium from the classroom method, many students/parents lost their jobs (part-time/full time), students experienced laggy internet speeds, and it might have been a possibility that they were attending their classes using outdated laptops/PCs (A sudden 
lockdown might not have given students the change to upgrade their equipment). This was in addition to the need to meet the deadlines of their assignments/projects. Hence, the aim of this study was to assess the prevalence of insomnia among university going students (medical, dental and nursing streams) in the South Asian Continent during the lockdown due to the COVID-19 pandemic.

\section{MATERIALS AND METHOD}

The present study was conducted amongst medical, dental and nursing undergraduate students residing in South Asia using convenience sampling from $\mathrm{or}^{\text {st }}$ June 2020 to $31^{\text {st }}$ August, 2020 after obtaining all necessary approvals (including ethical clearance) prior to start of the study.

Data was collected using a pre-tested and pre-validated questionnaire [the Athens Insomnia Scale (AIS), Soldatos et al (2000) $]^{10}$ using google forms, which is an 8-item questionnaire with each consisting of 4 parameters showing insomnia severity from none to very severe levels (o-3). Scores from each question are added to get the individual AIS score (range 0 -24). The higher the score was, the worse was the sleep quality. As per the scale, students with score of $\geq 6$ were considered insomniac.

The questionnaire was distributed among various social media websites as a link to ensure maximum participation. The first page informed the students about the study objectives, that participation in the study was voluntary and they could leave filing the questionnaire in between. By clicking on the "next" button, the respondent gave his consent to participate in the study. No personal particulars were collected to keep the data confidential.

Sample Size and Statistical analysis: Based on a pilot study among 25 students, the minimum sample required was 287 (OpenEpi Software) ${ }^{\mathrm{nl}}$ and to compensate for incomplete responses, the maximum sample was sought. Data Analysis was done using SPSS version 21.012 by using the independent samples t-test, and multiple logistic regression.

\section{RESULTS}

\section{Demographic details of the study population (table 1)}

A total of 921 entries were recorded, out of which 743 were complete and hence, were included in the study (response rate: $80.7 \%)$. There $219(29.5 \%)$ medical students, 301 (40.5\%) dental students while 223 (30\%) belonged to the nursing sciences. Their gender wise distribution is described in table 1. Insomnia was reported in $421(56.7 \%)$ students, out of which, the highest was seen among dental (62.7\%), followed by medical (59.8\%) and nursing (45.3\%) undergraduates.

\begin{tabular}{|c|c|}
\hline DESCRIPTION & $\mathrm{n}, \%$ \\
\hline Total Respondents & $743(100)$ \\
\hline - Medical UGs & $219(29.5)$ \\
\hline - Dental UGs & $301(40.5)$ \\
\hline - $\quad$ Nursing UGs & $223(30)$ \\
\hline Males & $299(40.2)$ \\
\hline Females & $514(59.8)$ \\
\hline Reported Insomnia & $421(56.7)$ \\
\hline - Medical UGs & $131(59.8)$ \\
\hline - Dental UGs & $189(62.7)$ \\
\hline - Nursing UGs & $101(45 \cdot 3)$ \\
\hline Reported Insomnia & \\
\hline • Males & $164(38.9)$ \\
\hline - Females & $257(61.1)$ \\
\hline
\end{tabular}

Table 1. Demographic Details of The Study Population

Responses to the Athens insomnia questionnaire (table 2)

The range of scores obtained by the respondents are shown in table 2. The highest range was observed among females (6-22) and dental students (6-21). Gender differences revealed a significant association among females $(\mathrm{p}=0.03)$ as compared to their male counterparts.

\section{Relationship between insomnia, gender and course pursued using multivariate regression analysis (table 3)}

The multiple linear regression model to analyze insomnia in relation to gender and course pursued revealed a statistical significant association in relation to gender with females being more affected $(\mathrm{p}=\mathrm{o.03})$, while no significant difference were observed in relation to the specialization of the student (table 3 ).

\section{DISCUSSION}

The results of the present study revealed a $56.7 \%$ prevalence of insomnia among medical, dental and nursing undergraduate students, and is on the higher end as compared to medical students of countries including Pakistan (40.74\%) ${ }^{13}$, Brazil, $(28.15 \%)$ and Iran $(42 \%){ }^{14}$ In contrast, Sing CY et al. reported a $68.8 \%$ prevalence of insomnia among a sample of Chinese college students. These differences can be due to socio- 


\begin{tabular}{|c|c|c|c|c|c|c|c|c|}
\hline \multicolumn{2}{|c|}{ QUESTIONS } & MALES & \multicolumn{2}{c|}{ FEMALES } & \multicolumn{2}{c|}{ P value } & \multicolumn{1}{c|}{ MEDICAL } & \multicolumn{2}{c|}{ DENTAL } & NURSING & p value \\
\hline Range & $3-20$ & $6-22$ & & $5-21$ & $6-21$ & $3-19$ \\
\hline Mean \pm SD & $13 \pm 2.45$ & $15 \pm 1.23$ & 0.03 & $11 \pm 3.52$ & $11 \pm 6.09$ & $10 \pm 2.22$ \\
\hline
\end{tabular}

Table 2. Responses to the Athens Insomnia Questionnaire (NS: Non Significant)

cultural beliefs, curriculum and individual stress levels of the student. ${ }^{15}$

The multiple linear regression model revealed that females were significantly more associated to have insomnia and these findings are in agreement to previous studies by various authors. ${ }^{2,16,17}$ In contrast, Pallos et al. ${ }^{18}$ reported males had a higher rate of insomnia as compared to females. Such increased statistics among females in the present study could be due to the fact that during lockdown, apart from studies, most females had to assist in homely work, which had significantly increased during the lockdown.

The results of the present study are consistent with the findings that students belonging to medical and allied sciences appear to be vulnerable to poor sleep due to duration and intensity of their curriculum, clinical duties and both pre-clinical clinical assignments. ${ }^{19}$ This burden can be assessed by the fact that as while researchers have estimated sleep disorders in the general population to be around $15-35 \%$, medical students showed a prevalence of insomnia of $30 \%{ }^{20}$ As per Jiang et al., who documented the prevalence of insomnia among university students from $9.4 \%$ to $38.2 \%$, the prevalence of insomnia among medical, dental and nursing students in on the higher side as stated above and as per the findings of the present study.

It is also to be noted that the present study was done during the lockdown period, which makes it unique in nature as a comprehensive literature search did not reveal any such study(ies) during this time. Therefore, the presence of insomnia directed in the present study could be higher as compared to pre-COVID times. However, the study meets the aim and objectives of the present study and respective councils and student bodies can implement regulations in place to reduce stress among students in the wake of another, god forbid, global pandemic.

The limitations of the present study could be the under/over reporting of data by the students, and social desirability bias. However, no personal details were collected and students were assured of the confidentiality of their data to reduce the probability of such a bias and it can be safely stated that the results of the present study can be generalized for the medical, dental and nursing students belonging to the South Asian continent.

\section{CONCLUSION}

Based on the results of the present study, a high prevalence of insomnia was found between medical, dental and nursing undergraduate students and there needs to be regular assessment of insomnia and stress among the students and preventive measures adopted incase a high prevalence of insomnia is found among them.

\section{REFERENCES}

1. Kaneita Y, Ohida T, Osaki Y, Tanihata T, Minowa M, Suzuki K. Insomnia Among Japanese Adolescents: A Nationwide Representative Survey. Sleep 2006;29(12):1543-50.

2. X.-1 Jiang, X.-y. Zheng, J. Yang, C.-p. Ye, Y.-y. Chen, et al. A systematic review of studies on the prevalence of Insomnia in university students. Public Health 2015; 129(12):1-6. https://doi.org/10.1016/j.puhe.2015.07.030. 3. Taylor DJ, Lichstein KL, Durrence HH. Insomnia as a health risk factor. Behav Sleep Med. 2003;1:227-247. 4. Liu X, Uchiyama M, Okawa M, Kurita H. Prevalence and correlates of self-reported sleep problems among

\begin{tabular}{|c|c|c|c|c|c|c|}
\hline & \multicolumn{2}{|c|}{ PREDICTOR } & COEFFICIENT & SD & \multicolumn{2}{c|}{ t } \\
\hline \multirow{2}{*}{ INSOMNIA } & Gender & -5.64 & 3.99 & 2.34 & $0.03^{*}$ \\
\cline { 2 - 7 } & Course Pursued & 21.2 & 2.33 & 6.54 & 0.08 \\
\hline
\end{tabular}

Table 3. Relationship Between Insomnia, Gender and Course Pursued Using Multivariate Regression Analysis 
Chinese adolescents. Sleep 2000;23:27-34.

5. Stewart R, Besset A, Bebbington P, et al. Insomnia comorbidity and impact and hypnotic use by age group in a national survey population aged 16 to 74 years. Sleep. 2006;29:1391-1397

6. Ohayon MM. Epidemiology of insomnia: what we know and what we still need to learn. Sleep Med Rev 2002;6(2):97e111.

7. Samaranayake CB, Arroll B, Fernando AR. Sleep disorders, depression, anxiety and satisfaction with life among young adults: a survey of university students in Auckland, New Zealand. N. Z Med J. 2014;127(1399):13e22.

8. Sarsour K, Van Brunt DL, Johnston JA, Foley KA, Morin CM, Walsh JK. Associations of nonrestorative sleep with insomnia, depression, and daytime function. Sleep Med 2010;11(10):965e72.

9. Kelly WE, Kelly KE, Clanton RC. The relationship between sleep length and grade-point average among college students. Coll Stud J. 2001;35:84-6.

10. Soldatos CR, Dikeos DG, Paparrigopoulos TJ. Athens insomnia scale: validation of an instrument based on ICD-10 criteria. Journal of Psychosomatic Research 2000;48 (6):555-60.

11. Dean AG, Sullivan KM, Soe MM. OpenEpi: Open Source Epidemiologic Statistics for Public Health, Version. www.OpenEpi.com, updated 2013/04/o6, accessed 2020/04/17.

12. IBM Corp. Released 2012. IBM SPSS Statistics for Windows, Version 21.o. Armonk, NY: IBM Corp.

13. Shakeel HA, Maqsood H, Ishaq A, Ali B, Hussain H,
Khan AR, et al. Insomnia among medical students: a cross-sectional study. Int J Res Med Sci. 2019 Mar;7(3):893-8. http://dx.doi.org/10.18203/23206012.ijrms20190944

14. Atkinson G, Davenne D. Relationship between sleep, physical activity and human health. Physiol Behav. 2007;90(2-3):229-35.

15. Sing CY, Wong WS. Prevalence of Insomnia and Its Psychosocial Correlates Among College Students in Hong Kong, Journal of American College Health 2010;59(3):174-82.

http://dx.doi.org/10.1080/o7448481.2010.497829

16. Voelker R. Stress, sleep loss, and substance abuse create potent recipe for college depression. J Am Med Assoc. 2004;291(18):2177e9.

17. Johnson EO, Roth T, Schultz L, Breslau N. Epidemiology of DSM-IV insomnia in adolescence: lifetime prevalence, chronicity, and an emergent gender difference. Pediatrics 2006;17(2):e247e56.

18. Pallos H, Gergely V, Yamada N, Miyazaki S, Okawa $M$. The quality of sleep and factors associated with poor sleep in Japanese graduate students. Sleep Biol Rhythms 2007:5:234e8

19. Wong JG, Patil NG, Beh SL, Cheung EP, Wong V, Chan LC, et al. Cultivating psychological well-being in Hong Kong's future doctors. Med Teach. 2005;27:715-9. 20. Foley DJ, Monjan AA, Brown SL, Simonsick EM, Wallace RB, Blazer DG. Sleep complaints among elderly persons: an epidemiologic study of three communities. Sleep. 1995;18(6):425-32. 